\title{
Lumped Parameter Network Simulation of a Loop Heat Pipe for Energy Management Systems in Full Electric Vehicles
}

Marco Bernagozzi ${ }^{\mathrm{a},{ }^{*}}$, Stene Charmer ${ }^{\mathrm{b}}$, Anastasios Georgoulas ${ }^{\mathrm{a}}$, Ileana Malavasi ${ }^{\mathrm{a}}$, Nicolas Michè ${ }^{\mathrm{a}}$, Marco Marengo ${ }^{a}$

${ }^{a}$ Advanced Engineering Centre University of Brighton, School of Computing, Engineering and Mathematics, Lewes Road, BN2 4GJ Brighton, UK

${ }^{b}$ Tata Motors European Technical Centre Plc, International Automotive Research Centre University of Warwick, Coventry, CV4 7AL, UK

*Corresponding Author: M.Bernagozzi@brighton.ac.uk

\begin{abstract}
Loop heat pipes (LHP) and other two-phase passive thermal devices, such as heat pipe loops (HPL), represent a very attractive solution for the energy management of systems characterized by a distributed presence of heating and cooling zones and by the needs of fast start-up, reliability, low cost and lightness. Even if the usual application for these devices is in the space sector, there could be a potential significant application for the automotive industry, for the development of embedded thermal networks for full electric vehicles (FEV), in order for example to recover the waste heat for cabin heating and cooling or to improve the aerodynamic efficiency. In the present investigation, the possibility to implement a new thermal control for an electric vehicle comprising from heat pumps (HP) and LHP, is here evaluated. In more detail, a 1-D lumped parameter model (LPM) that is able to predict the transient behaviour of a LHP in response of varying boundary and initial conditions, is developed and validated against literature experimental data. A novel methodology for treating numerically the condenser is proposed and validated for three different working fluids. An extensive parametric analysis is also conducted, showing the robustness of the thermal solution for different conditions and proving the possibility of using the proposed numerical code both for feasibility studies and for optimization purposes. A feasibility study utilizing the proposed model is also conducted and the results indicate that an array of LHPs can effectively transport heat from the motor section of the vehicle to the underbody, reducing significantly the aerodynamic losses.
\end{abstract}

Keywords: Loop Heat Pipe; Lumped Parameter; Electric Vehicle; Thermal Management

\section{Nomenclature}

\begin{tabular}{|c|l|c|l|}
\hline$A$ & Exchange surface $\left(\mathrm{m}^{2}\right)$ & $R_{d}$ & $\begin{array}{l}\text { Distributed hydraulic resistance } \\
\text { (bar s/kg) }\end{array}$ \\
\hline$c_{p}$ & Specific heat $(\mathrm{J} / \mathrm{kg} \mathrm{K})$ & $R_{p w v o}$ & $\begin{array}{l}\text { Thermal resistance primary } \\
\text { wick/vapour grooves (K/W) }\end{array}$ \\
\hline$g$ & Gravity $\left(\mathrm{m} / \mathrm{s}^{2}\right)$ & $R_{p w 2}$ & $\begin{array}{l}\text { Thermal resistance primary } \\
\text { wick/inlet bayonet (K/W) }\end{array}$ \\
\hline$H$ & Total enthalpy $(\mathrm{J})$ & $R_{\text {vowall }}$ & $\begin{array}{l}\text { Thermal resistance vapour } \\
\text { grooves/wall (K/W) }\end{array}$ \\
\hline$h$ & Specific enthalpy $(\mathrm{J} / \mathrm{kg})$ & $R_{\text {wallpw }}$ & $\begin{array}{l}\text { Thermal resistance wall/primary } \\
\text { wick (K/W) }\end{array}$ \\
\hline$h_{c}$ & Convection coefficient (W/K m $\left.{ }^{2}\right)$ & $r$ & Radius (m) \\
\hline$h_{L V}$ & $\begin{array}{l}\text { Specific enthalpy of vaporisation } \\
(\mathrm{J} / \mathrm{kg})\end{array}$ & $\bar{r}$ & Medium pore radius (m) \\
\hline$k$ & Thermal conductivity (W/m K) & $T$ & Temperature (K) \\
\hline$k_{c}$ & $\begin{array}{l}\text { Constant for pressure losses in a } \\
\text { turn }\end{array}$ & $T_{s a t}$ & Saturation temperature $(\mathrm{K})$ \\
\hline$k_{g}$ & Adiabatic index & $t$ & Time (s) \\
\hline$L$ & Length (m) & $t h i c k_{e v}$ & Evaporator wall thickness (m) \\
\hline$m$ & Mass (kg) & $u$ & Specific internal energy (J/kg) \\
\hline$\dot{m}$ & Mass flow rate (kg/s) & $V$ & Volume (m $\left.{ }^{3}\right)$ \\
\hline
\end{tabular}




\begin{tabular}{|c|c|c|c|}
\hline$P$ & Pressure (bar) & $v$ & $\begin{array}{l}\text { Fluid velocity/ Specific volume } \\
(\mathrm{m} / \mathrm{s}) /\left(\mathrm{m}^{3} / \mathrm{kg}\right)\end{array}$ \\
\hline$P^{*}$ & Reduced pressure & $x$ & Vapour quality \\
\hline$P r, R e$ & Prandtl and Reynolds numbers & $Z$ & Height $(\mathrm{m})$ \\
\hline$\dot{Q}_{c}$ & Heat lost at the condenser (W) & $\alpha_{f}$ & $\begin{array}{l}\text { Dittus-Boelter coefficient } \\
\left(\mathrm{W} / \mathrm{K} \mathrm{m}^{2}\right)\end{array}$ \\
\hline$\dot{Q}_{\text {ext }}$ & External power $(\mathrm{W})$ & $\Delta x$ & Length of the condenser node (m) \\
\hline$\dot{Q}_{\text {leak }}$ & Heat leakage $(\mathrm{W})$ & $\eta$ & Wick tuning parameter \\
\hline$\dot{Q}_{l l}$ & Heat lost at the liquid line $(\mathrm{W})$ & $\mu$ & Viscosity (Pa s) \\
\hline$\dot{q}$ & Heat balance resultant (W) & $\rho$ & Density $\left(\mathrm{kg} / \mathrm{m}^{3}\right)$ \\
\hline$R_{c}$ & $\begin{array}{l}\text { Concentrated hydraulic resistance } \\
\text { (bar s/kg) }\end{array}$ & $\sigma$ & Surface tension $(\mathrm{N} / \mathrm{m})$ \\
\hline$L H P$ & Loop Heat Pipe & $F E V / H E V$ & Full/Hybrid Electric Vehicle \\
\hline$L P N M$ & Lumped Parameter Network Model & $C C$ & Compensation Chamber \\
\hline \multicolumn{4}{|c|}{ Subscripts } \\
\hline bay & Bayonet & $V$ & Vapour \\
\hline$C C$ & Compensation Chamber & $V c$ & Vapour chamber \\
\hline$c /$ cond & Condenser & $v g$ & Vapour grooves \\
\hline$e$ & External & $\mathrm{vl}$ & Vapour line \\
\hline evap & Evaporator & Vo & Vapour Grooves outlet \\
\hline$i$ & Internal/node of the condenser & wall & Evaporator wall \\
\hline 1 & Liquid & 1 & Inlet of $\mathrm{CC}$ \\
\hline II & Liquid Line & 2 & Bayonet inlet \\
\hline$p w$ & Primary wick & $2 p$ & Two-phase \\
\hline$s W$ & Secondary wick & 3 & Bayonet inside the wick \\
\hline
\end{tabular}

\section{Introduction}

Worldwide, the growing request to move away from fossil fuels has further pushed the research of alternative sources of energy in the automotive industry. At the moment, one of the most promising solutions remains the development of full or hybrid electric vehicles (FEV and HEV), as important and innovative automotive companies have started to sell electric vehicles on a worldwide scale. A clear drawback of FEVs is the lack of a sufficient source of waste heat for the cabin thermal management. Therefore, the need of consumption of electric power for the HVAC system constitutes a considerable drawback in the overall efficiency of the vehicle. This could be addressed by the implementation of a Heat Pump with an efficient thermal network, enabling the use of waste heat. This requires the design and the implementation of a smart thermal management (STM) system characterised by high efficiency, lightness, low-cost and flexibility, able to transport heat at various operating temperatures. A perfect example of such systems is the loop heat pipe (LHP).

A LHP is a special type of heat pipe (HP), able to transfer heat for long distances ( 10-20 m) [1],[2]. It was developed in the Soviet Union in the early 1980s. The LHP differs from the standard wicked HP due to the fact that the wick is present in the evaporator only, allowing heat transfer for long distances, at a lower weight and cost. It is a two-phase flow based device that exploits cyclic phase-change (evaporation/condensation) of a working fluid, removing heat from a certain component and subsequently releasing it to a cold part. It is a passive device since the main motion force of the working fluid is the capillary action within the porous structure of the evaporator.

A LHP is composed by a wicked evaporator, a vapour line, a condenser, a liquid line and a compensation chamber, as illustrated in Fig. 1. When the evaporator is in contact with a hot source, the working fluid inside the wick evaporates and the action of capillarity makes the liquid to move and rewet the dry wick pushing the vapour to flow through the vapour line to the condenser. In the condenser, condensation occurs releasing heat to the surroundings. From the condenser, the liquid (usually subcooled) returns to the evaporator via the liquid line.

Inside the evaporator the liquid flows through the central bayonet (also called evaporator core), wets the so-called secondary wick (Fig. 1) and then moves to the primary wick. When heat is provided, evaporation occurs in the primary wick on which vapour grooves or channels are drilled. Hence, the vapour generated by evaporation, flows mostly into the vapour grooves, due to the lower pressure drop, while a smaller part flows through non-wicked passages (usually dug into the secondary wick) to the socalled compensation chamber (CC). The application of external heat causes the liquid to evaporate both at the outer and the inner side of the primary wick and this lost heat responsible for the inner side 
evaporation, known as heat leakage (or parasitic heat or back conduction), needs to be minimized through a specific design. It is usually estimated being $10 \%$ of the total heat [3].

The CC can be considered as part of the evaporator. It acts as a reservoir where both the liquid and vapour phases of the working fluid are present. In more detail, it receives vapour from the internal surface of the primary wick and provides condensed liquid to the secondary wick. Moreover, it provides a continuous flow of the working liquid to the secondary wick in the case that dry-out occurs. The most common manufacturing materials for a LHP are stainless steel and aluminium for the pipes and the container (evaporator wall), and titanium, copper and nickel for the wick structures. The most common working fluids are water, ammonia and methanol [4].
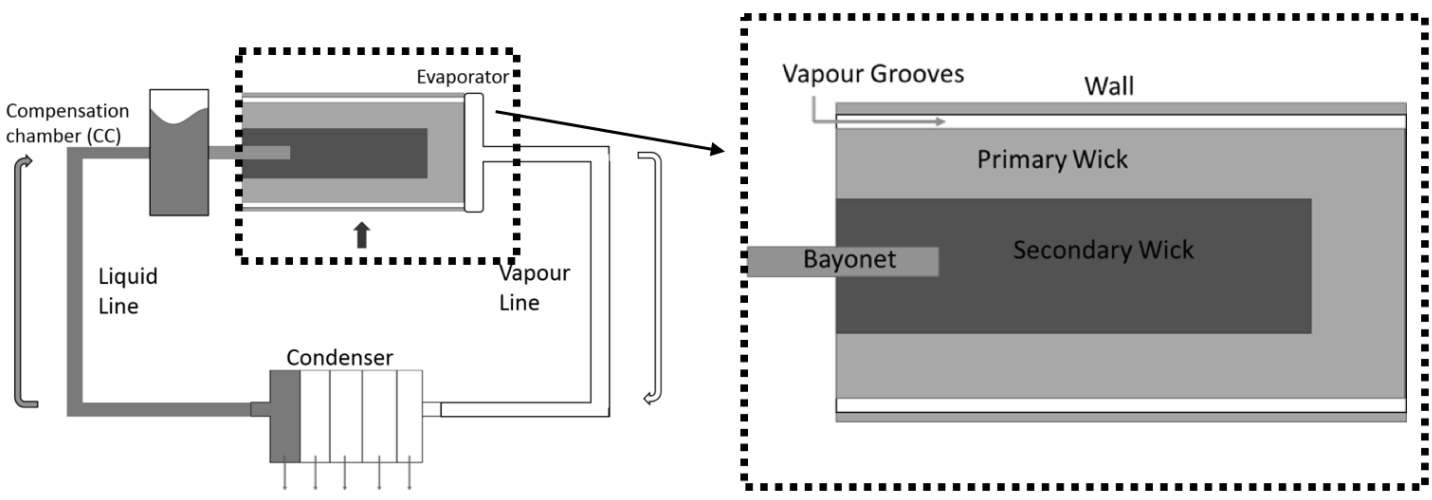

Fig. 1 - Loop Heat Pipe schematic.

In the recent years, extensive research work has been carried out on modelling and design for LHPs, especially for space applications. In 2005, Maydanik [2] published a review on developments, theoretical analysis and testing of LHP, reporting the different emerging types of LHPs: large, controllable, high heat flux, ramified, reversible, flat evaporators and miniature LHPs.

In 2012, Ambirajan et al. [4] summarized the fundamental thermodynamics behind the LHP operations, highlighting the studies on the different key factors such as filling ratio, evaporator configurations (flat or cylindrical; with or without bayonet), influence of different parameters on the start-up. Moreover, the authors reported several thermodynamic models on LHPs and a brief guideline on the main design aspects.

Regarding the application, it is worth pointing out two reviews published in 2014, Maydanik et al. [5] and Wang et al. [6], regarding LHP with flat evaporators and for solar heating applications, respectively. Flat-shaped evaporators are gaining a lot of attention for the fact that they will perfectly adapt to the surface of the electronic component to cool down, both in space and on ground. Solar heating is one of the more popular application for LHP that is not dedicated to the space environment only, and Wang et al. pointed out some interesting aspects on how to make cost effective LHPs, suggesting to consider real weather conditions and to assess the impact that they might have on economic, environmental and social aspects.

Quite a great number of works has been published on steady state numerical simulations of LHPs, summarized in the review by Siedel et al. [7], in which a three categories grouping is presented: complete LHP numerical models; numerical description of the evaporator only; analytical approaches.

Fewer works has been found on numerical models addressing the transient behaviour of the LHP. In 2008, Kaya et al. [8] presented a numerical model to simulate transient performance of a LHP, indicating how with low heat powers experimental investigation are needed to assess the heat leakage problem. In the same year, Vlassov et al. [9] created a transient mathematical model, coupling evaporator and CC with a thermal network, for an ammonia-LHP for space application. In 2009, Xin et al. [10] analysed the transient behaviour of a double LHP system for the Alpha Magnetic Spectrometer (AMS-02) present on the ISS, by means of SINDA/FLUINT. In the same field, the aerospace company Astrium developed a semi-explicit thermo-hydraulic model for both steady state and transient condition for design of LHP for space application [11].

The main objective of the present investigation is to understand the feasibility of the integration of a LHP in the heating/cooling distribution system of a FEV. A Lumped Parameter Model of the LHP is developed in order to assess the feasibility of implementing a thermal control system for a FEV, utilising an array of LHPs, for the direct heat control of the cabin (increasing passenger comfort) and the reduction of the cooling drag of the vehicle (increasing the aerodynamic performance). To the authors' best knowledge, this is the first case that this solution is investigated through a transient model. 
The proposed feasibility study was conducted in direct partnership with Tata Motors European Technical Centre (TMETC) inside an Innovate UK project. TMETC provided the necessary boundary and operating conditions (e.g. external heat transfer coefficients, required heat loads and geometry of FEV) utilising high resolution 3D Computational Fluid Dynamics Simulations (CFD).

\section{Lumped Parameter Network Model}

A lumped parameter network model (LPNM) represents the behaviour of a physical system concentrating different sub-components in discrete nodes, where the variables of interest are calculated under simplified assumptions. In this way, the complexity of integrating the mass, momentum and energy balance equations along actual geometries are avoided, and this is particularly useful when the system is large compared with the scale of the phenomena, such as in presence of phase-change. In fact, a CFD analysis of flows in porous structures with phase change in a system with a global length of several meters may become unfeasible, and only a hybrid approach [12] may be a good alternative with respect to the method used in the present paper. For LPNM, the thermal electrical [13] and hydraulic electrical [14] analogies are typically used to analyse the system. Their principal features are listed in the following table.

Table 1 - Electric analogies. $R_{t}$ is the thermal resistance, $R_{d}$ is the pressure resistance associated to the distributed losses and $\mathrm{R}_{\mathrm{c}}$ is the pressure resistance associated to the concentrated losses.

\begin{tabular}{|c|c|c|c|}
\hline \multicolumn{1}{|c|}{$\begin{array}{c}\text { Parameter } \\
\text { (value at the nodes) }\end{array}$} & $\begin{array}{c}\text { Electrical } \\
\text { Electric Potential }\end{array}$ & $\begin{array}{c}\text { Thermal } \\
\text { Temperature }\end{array}$ & $\begin{array}{c}\text { Hydraulic } \\
\text { Pressure }\end{array}$ \\
\hline $\begin{array}{c}\text { Flux } \\
\text { (value travelling through the network lines) }\end{array}$ & $\begin{array}{c}T \\
\text { Current }\end{array}$ & $\begin{array}{c}\dot{Q} \\
\text { Heat Transfer Rate Volumetric flow rate }\end{array}$ \\
\hline Resistance & $R$ & $R_{t}$ & $\dot{m}_{v}, R_{c}$ \\
\hline Fundamental Law & $\Delta V=R I$ & $\begin{array}{c}\Delta T=\dot{Q} R_{t} \\
\text { Ohm's Law }\end{array}$ & $\begin{array}{c}\Delta P=\dot{m}_{v}\left(R_{d}\right) \\
\text { Pewton's Law }\end{array}$ \\
\hline
\end{tabular}

The final mathematical form of this approach is a simplified ordinary differential equation system (ODE) for transient conditions. Hence, an approximate, but still accurate solution is achieved, reducing significantly the computational time. The proposed LPNM code consists of a module for the start-up and four additional modules (evaporator, liquid and vapour line, and condenser) in accordance to the actual components division of the simplified system (Fig. 1).

The general model assumptions are: the model is one dimensional; the liquid is assumed to be incompressible; vapour is assumed to be compressible and it is treated as ideal gas; the vapour line is assumed to be adiabatic; the working fluid physical properties are calculated as function of temperature and/or pressure, employing polynomial fits obtained by empirical data [15].

This proposed model stands out as allows to perform transient simulation (most of the LPNM are steadystate) and it introduces a novel numerical treatment for the condenser analysis. Moreover, the model adapts the condenser nodes in order to ensure mass conservation with different integration time step and boundary conditions.

\subsection{Start-Up model}

Aiming at reproducing numerically a realistic, transient application, all the LHP parts at the beginning are at the same ambient temperature $T_{a m b}$. The chosen start-up scenario is when the liquid fills completely both the wick and the bayonet, with vapour present only in the vapour grooves. Consequently, the vapor expands immediately as soon as the external heat load is applied [16] and the fluid assumes the corresponding saturation pressure at the initial ambient temperature. Since the LHP is a closed system with known, constant total specific volume $v_{f r}$, the transient condition has to be treated as an isochoric heating, and pressure needs to be incremented accordingly until the corresponding temperature at the condenser and the liquid line is high enough to be able to dissipate the total heat input.

The procedure is to "chase" the pressure corresponding to the new value of internal energy of the liquidvapour mixture, given by the following equation:

$$
u\left(t_{i+1}\right)=u\left(t_{i}\right)+\frac{\dot{q} \Delta t}{m_{\text {evap }}}
$$


where the internal energy of the mixture is obtained by the following equation $u=x u_{v}+(1-x) u_{l}$ in which the initial vapour quality is estimated by the initial specific volume, i.e. filling ratio, $x=\left(v_{f r}-\right.$ $\left.v_{l}\right) /\left(v_{v}-v_{l}\right)$

This operation is then repeated for every time step according to the classical heat balance equation:

$$
\dot{Q}_{\text {ext }}=\dot{Q}_{c}+\dot{Q}_{l l}+m_{\text {evap }} \frac{d T_{\text {evap }}}{d t}
$$

where $\dot{Q}_{c}$ and $\dot{Q}_{l l}$ are the heat dissipated respectively at the condenser and at the liquid line (the vapour line is adiabatic). From equation (2), the parameter $\dot{q}$ in equation (1) can be easily derived:

$$
\dot{q}=\dot{Q}_{e x t}-\dot{Q}_{c}-\dot{Q}_{l l}-\frac{m_{\text {evap }}\left(d T_{\text {evap }}\right)}{d t}=\dot{Q}_{\text {ext }}-\dot{Q}_{c}-\dot{Q}_{l l}-\frac{m_{\text {evap }}\left(\Delta T_{\text {evap }}\right)}{\Delta t}
$$

To conclude the start-up calculations, the mass flow rate is obtained as:

$$
\dot{m}=\frac{\dot{Q}_{\text {ext }}}{h_{L V}}
$$

where $h_{L V}$ is the heat of vaporisation.

\subsection{Evaporator model}

It was deemed appropriate to decouple the compensation chamber from the evaporator and analyse these two domains separately. The proposed configuration is represented schematically in Fig. 2.

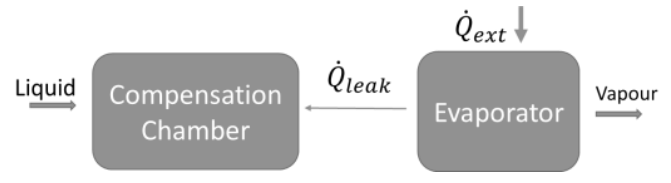

Fig. 2. Evaporator / Compensation Chamber schematic.

From the liquid line, liquid enters the compensation chamber. Therefore, it can be assumed that the liquid inside the bayonet and inside the $\mathrm{CC}$ has the same temperature $\left(T_{c c}=T_{2}\right)$. Since the $\mathrm{CC}$ always contains both liquid and vapour, $T_{c c}$ was considered as the saturation temperature for that node.

Applying the energy balance equation to the compensation chamber domain:

$$
\dot{Q}_{\text {ext }}+\dot{Q}_{\text {leak }}=\dot{m} c_{p}\left(T_{1}-T_{c c}\right)+m_{c c} c_{p, c c} \frac{d T_{c c}}{d t}
$$

leaves $T_{c c}$ as the only unknown since $T_{1}$ is known from the liquid line last node.

Using the calculated value of $T_{c c}$ from equation (5), the pressure in the $\mathrm{CC}$ can be also estimated $\left(P_{c c}=\right.$ $\left.f_{\text {sat }}\left(T_{c c}\right)\right)$.

The thermal network in Fig. 3 represents the evaporator, with arrows representing the heat flow directions. Writing the balance equation for every node gives the ODE system that can be solved for obtaining the temperature values:

$$
\begin{aligned}
& \frac{d T_{v o}}{d t}=\left[+\frac{T_{v o}-T_{p w}}{R_{p w v o}}-\frac{\left(T_{v o}-T_{\text {wall }}\right)}{R_{\text {vowall }}}+\dot{m} c_{p, v}\left(T_{\text {sat }}-T_{v o}\right)\right] \frac{1}{m_{v o} c_{p, v}} \\
& \frac{d T_{p w}}{d t}=\left[+\frac{T_{p w}-T_{v o}}{R_{p w v o}}-\frac{T_{p w}-T_{\text {wall }}}{R_{\text {wallpw }}}-\frac{T_{p w}-T_{\mathrm{cc}}}{R_{p w 2}}-\dot{Q}_{\text {leak }}-\dot{m} h_{L V}\right] \frac{1}{m_{p w} c_{p w}} \\
& \frac{d T_{\text {wall }}}{d t}=\left[-\frac{T_{\text {wall }}-T_{v o}}{R_{\text {vowall }}}-\frac{T_{\text {wall }}-T_{p w}}{R_{\text {wallpw }}}+\dot{Q}_{\text {ext }}\right] \frac{1}{m_{\text {wall }} c_{\text {pwall }}}
\end{aligned}
$$

where the signs result according to the arrow directions in Fig. 3. The first equation represents the balance at the vapour grooves node. Equation (7) represents the balance at the primary wick node considering the heat leakage and enthalpy of vaporisation as well. The last equation represents the balance at the evaporator wall node. 


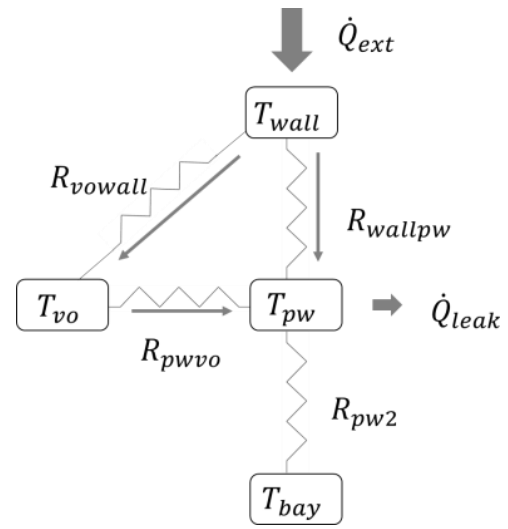

Fig. 3. Thermal Network of the evaporator.

In equation (6), in addition to the sensible heat terms, also the enthalpy difference between inlet and outlet of the vapour grooves is considered, in order to take into account the amount of superheat. In the primary wick, the removal of the latent heat is taken into account through the last term in equation (7), within the brackets.

Below the thermal resistances are reported:

$$
\begin{aligned}
R_{p w v o}= & \frac{1}{h_{c v g} A_{v g}}+\frac{\ln \left(\frac{r_{p w}}{r_{s w}}\right)}{2 \pi k_{p w} L_{p w}} \\
R_{\text {vowall }}= & \frac{1}{h_{c v g} A_{v g}}+\frac{\ln \left(\frac{r_{p w}+\text { thick }}{r_{p w}}\right)}{2 \pi k_{w a l l} L_{p w}} \\
R_{p w 2}= & \frac{\ln \left(\frac{r_{p w}}{r_{s w}}\right)}{2 \pi k_{p w} L_{p w}}+\frac{\ln \left(\frac{r_{s w}}{r_{b a y, e}}\right)}{2 \pi k_{s w} L_{s w}}+\frac{1}{h_{c, b a y} A_{b a y}} \\
R_{\text {wallpw }}= & \frac{\frac{\ln \left(\frac{r_{p w}}{r_{s w}}\right)}{2 \pi L_{p w} k_{p w}} \cdot \frac{1}{h_{c v g} A_{v g}}}{\ln \left(\frac{r_{p w}}{r_{s w}}\right)}+\frac{\ln \left(\frac{r_{p w}+\text { thick } k_{e v}}{r_{p w}}\right)}{2 \pi k_{w a l l} L_{p w}} \\
& \frac{1}{h_{c v g} A_{v g}}+\frac{L_{p w} k_{p w}}{2 \pi L_{p}}
\end{aligned}
$$

where $h_{c, v g}=3.66 \frac{k_{l}}{2 r_{v g}}[3]$ is the convection coefficient inside the vapour grooves.

Looking at the pressure values, starting from pressure $P_{1}$ and using the electric-hydraulic analogy the pressure inside the bayonet $\left(P_{3}\right)$ can be calculated:

$$
\begin{array}{ll}
P_{2}=P_{1}-\dot{m} R_{d 12} & R_{d 12}=\frac{8 \mu_{l} L_{c c}}{\rho_{l} \pi r_{c c, i}^{4}} \\
P_{3}=P_{2}-\dot{m} R_{d 23} & R_{d 23}=\frac{8 \mu_{l} L_{b a y}}{\rho_{l} \pi r_{b a y, i}^{4}}
\end{array}
$$

In order for the fluid to circulate inside the device, a positive $\Delta P_{\text {cap }}$ due to capillarity needs to be applied by the wicks, governed by the Laplace-Young equation [17]:

$$
\Delta P_{c a p}=\frac{2 \sigma}{\bar{r}} \cos \theta
$$

where $\bar{r}$ is the medium pore radius and $\theta$ is the equilibrium contact angle of the menisci in the wick pores. In steady-state conditions $\Delta P_{\text {cap }}$ compensates the sum of all the pressure drops along the LHP. Thus, the pressure balance equation is the following:

$$
\Delta P_{c a p}=\Delta P_{v o}+\Delta P_{v l}+\Delta P_{c o n d}+\Delta P_{l l}+\Delta P_{b a y}
$$

Given the small size of the pipe, the hydraulic inertia of the fluid is not considered.

Since equation (11) contains two terms, such as $\bar{r}$ and wettability, which are rarely given by the experimenters, a parameter $\eta$ was added to tune the pressure terms:

$$
P_{s w}=P_{3}+\eta \frac{2 \sigma}{\bar{r}}_{s w}
$$




$$
P_{p w}=P_{s w}+\eta \frac{2 \sigma}{\bar{r}_{p w}}
$$

The accuracy of this assumption is assured by the fact that the curvature of the menisci changes naturally in order to have a capillary pressure which balances the total pressure drop in the loop [18]. To close the pressure side analysis for the evaporator, the pressure drop inside the vapour grooves is calculated:

$$
\begin{gathered}
P_{v o}=P_{p w}-\dot{m} R_{d v g} \\
R_{d v g}=\frac{8 \mu_{v} L_{v g}}{\rho_{v} \pi r_{v g, i}^{4}}
\end{gathered}
$$

\subsection{Vapour Line model}

Vapour is assumed to be an ideal and compressible gas, and the vapour line is adiabatic. Therefore standard polytropic relations with exponent $k_{g}$ are used [19]:

$$
T P^{\frac{1-k_{a}}{k_{g}}}=\cos t
$$

where $k_{g}=\frac{c_{p}}{c_{v}}$ is the adiabatic index.

From the evaporator values, temperature and pressure at the start of the vapour line are known, hence:

$$
P_{i+1}=P_{i}-\dot{m}\left(R_{d, i}+R_{c, i}\right)+g \rho_{v} \Delta z_{v l}
$$

where $R_{c}=\frac{k_{c} v}{2 \pi r_{i}^{2}}$ and $k_{c}$ is a parameter that takes into account the additional pressure loss given by a turn [20].

In eq. (20), the $i$ subscript is the node number and the last term is the pressure drop due to gravity, which depends from the position of the condenser with respect to the evaporator, i.e., if the latter is at a higher elevation $\Delta z_{v l}$, will have a negative sign.

$$
\begin{aligned}
& T_{i+1}=T_{i}\left(\frac{P_{i}}{P_{i+1}}\right)^{\frac{1-k_{g}}{k_{g}}} \\
& \rho_{i+1}=\rho_{i}\left(\frac{P_{i+1}}{P_{i}}\right)^{\frac{1}{k_{g}}} \\
& v_{i+1}=\frac{\dot{m}}{\rho_{i+1} \pi r_{i}^{2}}
\end{aligned}
$$

This sequence will be executed for every node resulting in the calculation of the values for temperature and pressure at the inlet of the condenser.

\subsection{Condenser model}

The first node of the condenser is considered to have a vapour quality of one, assuming that no early condensation happens inside the vapour line. The vapour superheat is not common and desirable, so this has been disregarded. Working fluid properties when the considered regime is two-phase flow are calculated using the following empirical relations:

- Internal convective heat transfer coefficient (Shah's Correlation [21]):

$$
h_{c, i}=\alpha_{f}\left[(1-x)^{0.8}+\frac{3.8 x^{0.76}(1-x)^{0.04}}{P^{*^{0.38}}}\right]
$$

where $\alpha_{f}=0.023 \operatorname{Re}^{0.8} \mathrm{Pr}^{0.3} \frac{k_{l}}{2 r_{i}}$ is the liquid convection coefficient from Dittus-Boelter [21] and $P^{*}$ is the reduced pressure;

- Two-phase density:

$$
\rho_{2 p}=x \rho_{v}+(1-x) \rho_{l}
$$

- Two-phase viscosity [22]:

$$
\mu_{2 p}=\mu_{l}-2.5 \mu_{l}\left(\frac{x \rho_{l}}{x \rho_{l}+(1-x) \rho_{v}}\right)^{2}+\left(\frac{x \rho_{l}\left(1.5 \mu_{l}+\mu_{v}\right)}{x \rho_{l}+(1-x) \rho_{v}}\right)
$$


The total number of condenser nodes $n_{c}$ is obtained considering that the mass inside the single node should be equal to the quantity of working fluid passing through the node multiplied by the integration time step:

$$
\begin{gathered}
m_{i}=\rho_{l} \pi r_{i}^{2} L_{x}=\rho_{l} \pi r_{i}^{2} \frac{L_{\text {cond }}}{n_{c}} \\
n_{c}=\frac{\rho_{l} \pi r_{i}^{2} L_{\text {cond }}}{m_{i}}=\frac{\rho_{l} \pi r_{i}^{2} L_{\text {cond }}}{\dot{m} h_{\text {step }}}
\end{gathered}
$$

Since the mass flow rate is a function of the external heat, the number of nodes are also function of the external heat. Therefore, the lower the heat input, the higher is the necessary number of nodes and thus the computational time.

The iterative procedure starts from the pressure evaluation:

$$
P_{i}=P_{i-1}-\dot{m}\left(R_{d}+R_{c}\right)
$$

The equations of conservation for energy and mass for each node $i$ are:

$$
\begin{array}{cc}
\text { Energy } & \frac{d H_{i}}{d t}=\frac{d\left(m_{v} h_{v}+m_{l} h_{l}\right)}{d t}=\dot{Q}_{c, i}+\dot{m}\left(h_{i-1}-h_{i}\right) \\
\text { Mass } & m_{i-1}+\frac{d m_{i}}{d t}=m_{i}
\end{array}
$$

From the mass balance, since there is no mass variation in time in the single control volume representing node $i$ (i.e. there is no mass storage in the node):

$$
\begin{gathered}
\frac{d m_{i}}{d t}=\frac{d\left(m_{v}+m_{l}\right)}{d t}=\frac{d\left(\rho_{l} V_{l}\right)}{d t}+\frac{d\left(\rho_{v} V_{v}\right)}{d t}=0 \\
\rho_{l} \frac{d V_{l}}{d t}=-\rho_{v} \frac{d V_{v}}{d t}
\end{gathered}
$$

This allows to further expand equation (26):

$$
\left.\frac{d\left(\rho_{v} V_{v} h_{v}\right)}{d t}\right|_{i}+\left.\frac{d\left(\rho_{l} V_{l} h_{l}\right)}{d t}\right|_{i}=\dot{Q}_{c, i}+\dot{m}\left(h_{i-1}-h_{i}\right)
$$

Both vapour and liquid enthalpies are functions of the temperature only, and, since equilibrium phasechange processes are considered, the temperature is constant for a given pressure, and therefore also $h_{v}$ and $h_{l}$ are constant. Moreover, density values $\rho_{v}$ and $\rho_{l}$ are calculated from the two-phase relations as a function of the pressure difference between two nodes, thus they can exit the derivative too:

$$
\begin{aligned}
& \left.\rho_{l} h_{l} \frac{d V_{l}}{d t}\right|_{i}+\left.\rho_{v} h_{v} \frac{d V_{v}}{d t}\right|_{i}=\dot{Q}_{c, i}+\dot{m}\left(h_{i-1}-h_{i}\right) \\
& -\left.\rho_{l} h_{L V} \frac{d V_{l}}{d t}\right|_{i}=\dot{Q}_{c, i}+\dot{m}\left(h_{i-1}-h_{i}\right)
\end{aligned}
$$

where:

- $h_{L V}=h_{v}-h_{l}$ is the enthalpy of vaporisation;

- $h_{i-1}-h_{i}$ is the difference of enthalpy between two adjacent nodes;

- $Q_{c, i}$ is the heat loss to the cold source at every node, defined according to

$$
\dot{Q}_{c, i}=\frac{T_{c}-T_{i}\left(P_{i}\right)_{s a t}}{R_{t, i}}
$$

where the temperature of the node is calculated from the solution of the pressure problem.

Coming back to equation (32), considering that $V_{l}=\frac{m_{l}}{\rho_{l}}=\frac{m_{t o t}(1-x)}{\rho_{l}}$, it is possible to express the differential equation of the condenser as a function of vapour quality only:

$$
\begin{aligned}
& -h_{L V} \frac{d\left((1-x) m_{t o t}\right)}{d t}=\frac{T_{c}-T_{i}\left(P_{i}\right)_{s a t}}{R_{t, i}}+\dot{m}\left(h_{i-1}-h_{i}\right) \\
& -h_{L V} \frac{d(1-x)}{d t} m_{t o t}-h_{L V}(1-x) \frac{d m_{t o t}}{d t}=\frac{T_{c}-T_{i}\left(P_{i}\right)_{s a t}}{R_{t, i}}+\dot{m}\left(h_{i-1}-h_{i}\right)
\end{aligned}
$$

Since the total mass in the node is constant $\frac{d m_{t o t}}{d t}=0$ and therefore from equation (34), 


$$
\left.\frac{d x}{d t}\right|_{i}=\frac{T_{c}-T_{i}\left(P_{i}\right)_{s a t}}{R_{t, i} m_{i} h_{L V}}+\frac{\dot{m}}{m_{t o t}} \frac{\left(h_{i-1}-h_{i}\right)}{h_{L V}}
$$

This approach, to the author's best knowledge, is a novel treatment regarding the numerical description of the condenser behaviour.

\subsection{Liquid Line model}

The liquid is incompressible and subcooled, and the temperature of the surroundings $T_{a m b}$ is known from the boundary conditions.

The heat exchange at the node is equal to:

$$
Q_{l l, i}=\frac{T_{a m b}-T_{i}}{R_{t, i}}
$$

where:

- $R_{t, i}=\frac{1}{h_{c e, i} A_{e, i}}+\frac{1}{h_{c i, i} A_{i, i}}$;

- $h_{c i, i}=0.023 \operatorname{Re}^{0.8} \operatorname{Pr}^{n d b} \frac{k_{l}}{2 r_{i}}$ with $n d b$ being Dittus-Boelter coefficient which is 0.4 for heating and 0.3 for cooling [23] and $h_{c e, i}$ depending on the application;

For the pressure:

$$
\left.P_{i+1}-P_{i}=\dot{m}\left(R_{d, i}+R_{c, i}\right)\right)-g \rho_{l} \Delta z_{l l}
$$

where $g \rho_{v} \Delta z_{l l}$ is the pressure drop due to gravity, which in this case assists the fluid motion.

To close the solution cycle:

$$
\begin{gathered}
Q_{a m b, i}=\dot{m}\left(h_{i+1}-h_{i}\right) \\
\Delta h=\frac{Q_{a m b, i}}{\dot{m}}=c_{p} \Delta T \\
T_{i+1}=T_{i}-\frac{Q_{a m b, i}}{\dot{m} c_{p}}
\end{gathered}
$$

The temperature of the last node of the liquid line is the new $T_{1}$ for the evaporator at the following time step, and thus the loop is repeated.

\section{Numerical validation}

In order to validate the developed LHP model, literature available experimental measurements were used. Satisfactory results were obtained reproducing the results by Pouzet et al. [24], Tharayil et al.[25] and Chen et al. [26].

In the first paper [24] the aim of the authors was to investigate the instability of the cyclic behaviour of the device, with particular attention to the liquid-vapour interface in the compensation chamber and the reservoir. The procedure is to examine the response to both upward and downward swings of the externally applied heat, comparing experimental results with their simulations. The externally applied heat power was varied from $200 \mathrm{~W}$ to $400 \mathrm{~W}$ and then back to $200 \mathrm{~W}$. The working fluid is R134a and the chosen materials are Fortal ${ }^{\circledR}$ Aluminium Alloy for the evaporator, copper for the condenser, vapour line and liquid line tubes and steel for the compensation chamber.

In the following figures a comparison between the numerical and experimental results of the chosen paper with the numerical results of the present work is conducted. On Fig. 4 the comparisons between the temperatures of the evaporator wall and of the compensation chamber are illustrated. On Fig. 5 there is the comparison of the mass flow rates and the temperatures of the vapour grooves and the primary wick, that in the paper of Pouzet et al. are described as the temperatures above and below the meniscus. 
a) Evaporator Wall

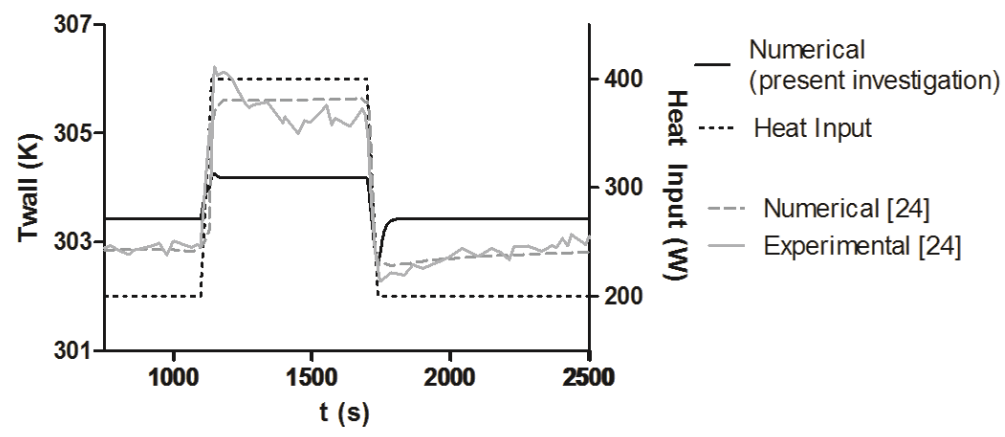

b) Compensation Chamber

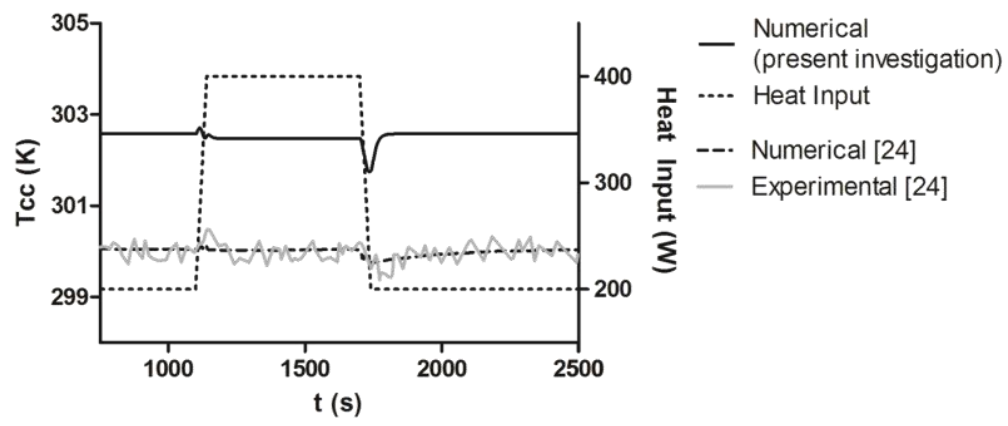

Fig. 4 - Comparison between Evaporator wall temperatures (a) and compensation chamber temperature (b)

c) Mass Flow Rate

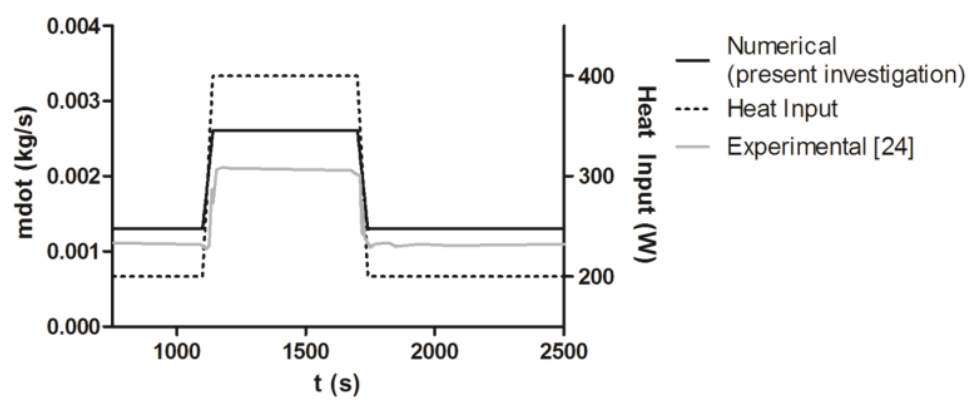

d) Primary wick and Vapour grooves

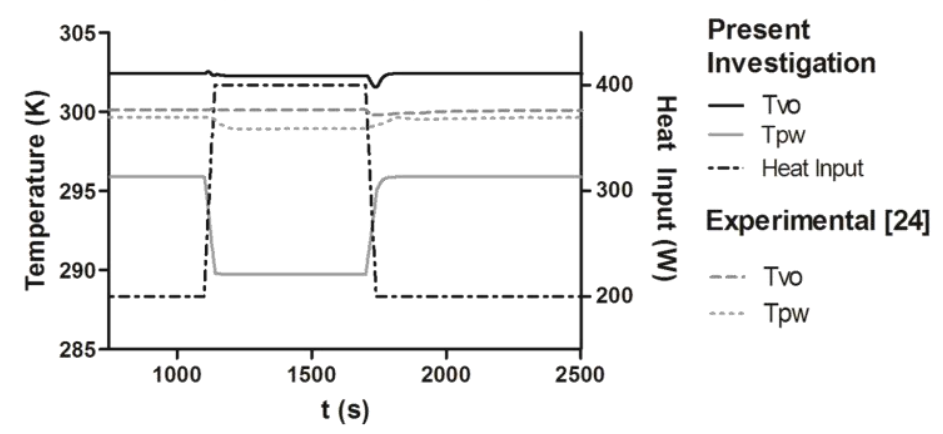

Fig. 5 - Mass flow rate comparison (c) and primary wick and vapour grooves temperatures comparison (d) 
From Fig. 4 (a) the comparison indicates that the model is able to capture the trend of the evaporator wall temperature with a small average error $(0.03 \%)$, and it also predicts the overshoot in the upward variation of external heat, something that was not captured by the corresponding numerical model in [24]. Fig. 4 (b) shows the comparison of the compensation chamber temperature evolution with time. The temperature error is close to the evaporator wall error $(-0.9 \%)$ and the prediction of the overshoot is still present. The variation of the mass flow rate that is depicted in Fig. 5 (c) reveals an acceptable prediction of the experimental values. The over prediction by $22 \%$ is due to the implicit imprecision inherent in the fitted polynomial equation used to calculate the latent heat of vaporization.

A comparison between the primary wick and vapour grooves temperatures in also shown in Fig. 5 (d). The present model is able to predict the particular, opposite trends of the two nodes (increasing for $T_{v o}$ and decreasing for $T_{p w}$, as shown in the right hand side of Fig. 5). In this case the model provides a temperature prediction that is slightly further away from the experimental value, especially for $T_{p w}$ ($0.74 \%$ of error for the vapour grooves temperature and $1.84 \%$ for the primary wick temperature). In the analysed work [24], it is suggested that this inverse pattern between the wick and the vapour grooves allows the evaporator to be thermally stable.

In the second paper [25], the aim was to study the effect of different filling ratios on the heat transfer performance of a novel miniature LHP. A particular finned geometry was used for the evaporator in order to increase the allowable heat flux. The LHP was made of copper and the working fluid was water. In the present work the response of the temperatures to varying heat load conditions is numerically reproduced. Following is the comparison between the evaporator wall temperatures having a step-wise increment in the external heat of $40 \mathrm{~W}$ each step, from $40 \mathrm{~W}$ up to $380 \mathrm{~W}$ :

Validation Water

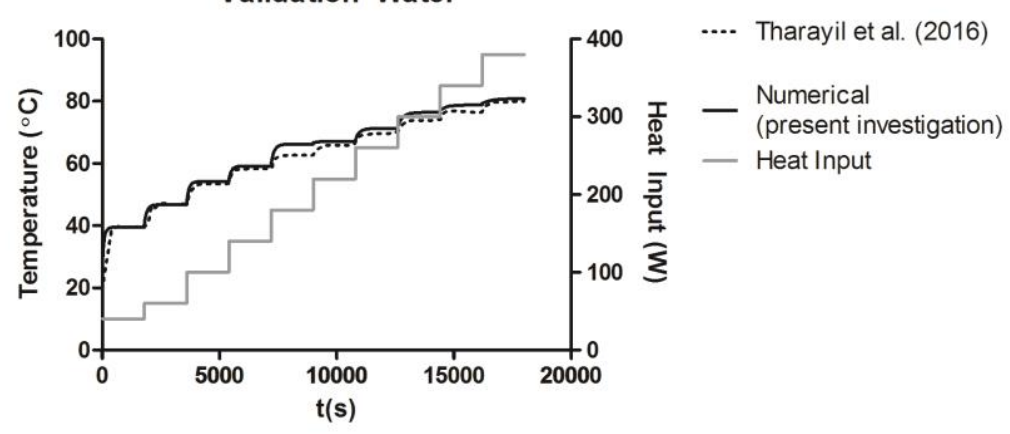

Fig. 6 - Comparison of evaporator wall temperatures with [25]

Fig. 6 shows an excellent agreement between the experiment and the numerical simulations, leading to an average error of $-0.42 \%$.

For the third paper ([26]), the LHP has a disk-shaped evaporator, in order to find the maximum heat load. The tube material is stainless steel and the working fluid is ammonia. Following is the proof of the validation with two different cycles of heat load variations, considering two nodes in the evaporator, the wall and the primary wick: 


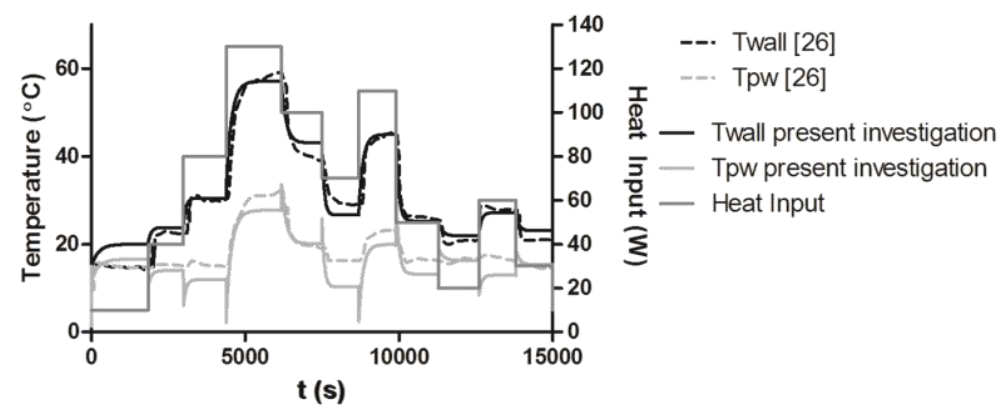

\section{Comparison with Chen et al (2012) (b)}

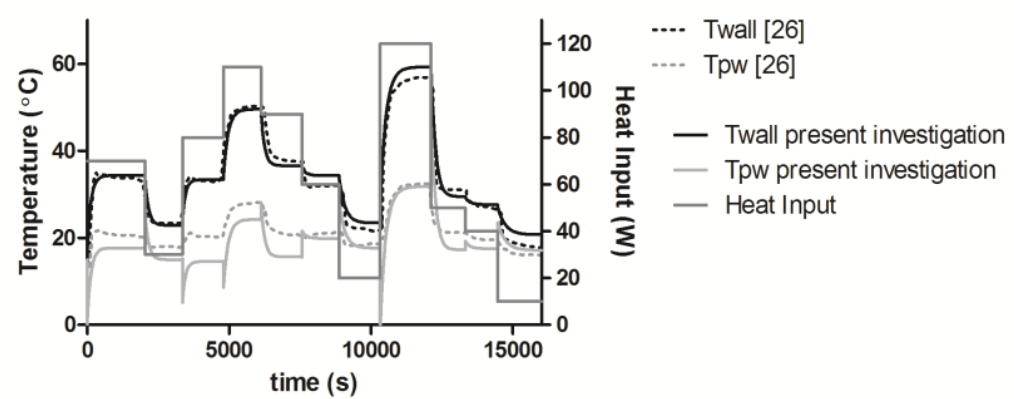

Fig. 7 - Comparison of evaporator wall and primary wick temperatures with [26], in (a) the power cycle is 10-4080-130-100-70-110-50-20-60-30 W whereas for (b) is 70-30-80-110-90-60-20-120-50-40-10 W

Fig. 7 shows again a very good prediction of the experimental results with an average error of $-0.27 \%$ on $T_{w a l l}$ and $0.68 \%$ for $T_{p w}$ for case (a) and $-0.21 \%$ and $0.90 \%$ for case (b), respectively. The two cases present similar errors for the two nodes, nevertheless there is a slightly bigger error in the prediction of the primary wick, since in the lumped parameter model this node considers also the solid properties of the wick, not only the working fluid.

\section{Parametric Analysis}

\subsection{Parametric Analysis Results}

In order to be able to realise a proper LHP design, understanding the effect of variation of the values of underpinning variables is essential. Simulations are carried out with an increase and decrease of each of the selected parameters in a range from $-20 \%$ to $+20 \%$, studying the effect of this variation on the major LHP performance parameters. The 12 varied parameters chosen are:

1. condenser internal radius $r i_{\text {cond }}$;

2. condenser pipe thickness $r e_{\text {cond }}$;

3. evaporator wall thickness $t_{\text {hickev }}$;

4. condenser length $L_{\text {cond }}$;

5. primary wick radius $r_{p w}$;

6. primary wick length $L_{p w}$;

7. porosity of the wicks;

8. vapour groove radius $r_{v g}$;

9. vapour grooves number $n_{v g}$;

10. liquid line and vapour line internal radii $r i_{l l} / r i_{v l}$;

11. heat leakage $Q_{\text {leak }}$ from the grooves back to the CC

12. length of the liquid $\left(L_{l l}\right)$ and vapour line $\left(L_{v l}\right)$.

The performance parameters are vapour quality, maximum temperature, total thermal resistance, start up time and maximum pressure.

This analysis has been performed on the geometries and fluids (ammonia, water and R134a) of the three papers used for the validation. The results are presented in the following figures. 

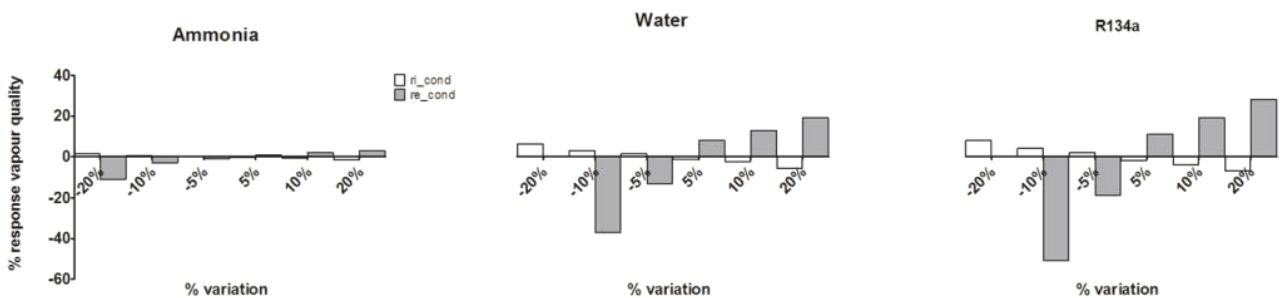

368
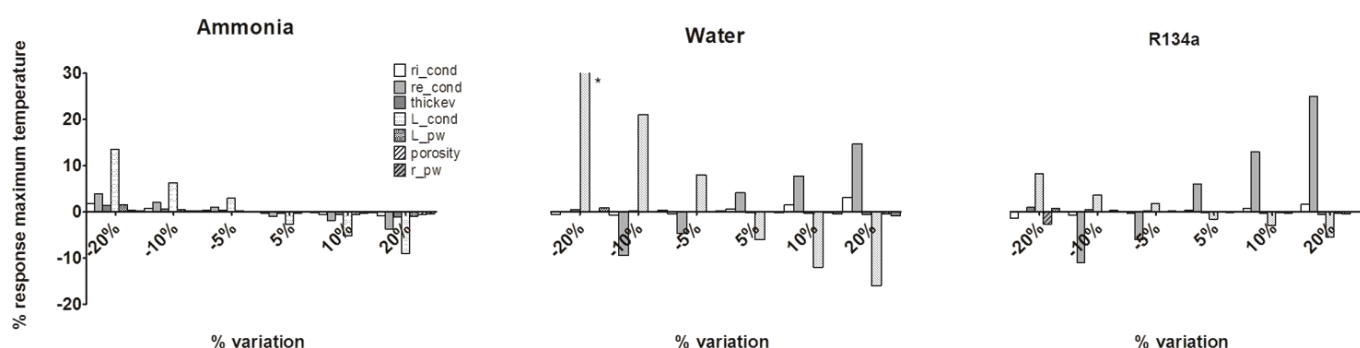

369
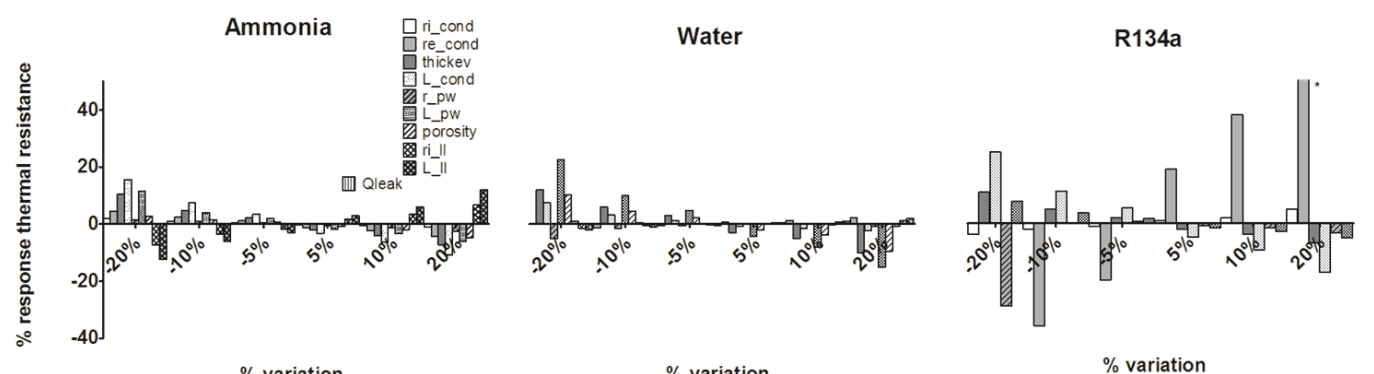

370

$$
\% \text { variation }
$$

$\%$ variation

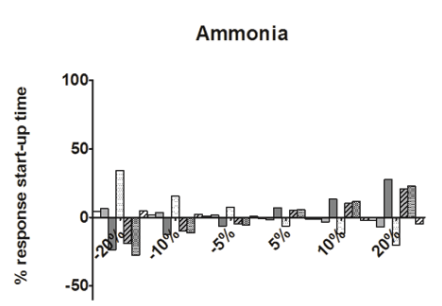

Water

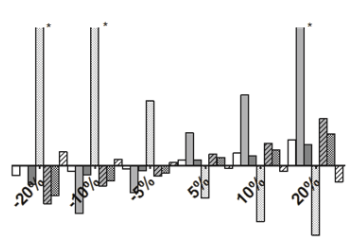

R134a

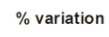

$\%$ variation
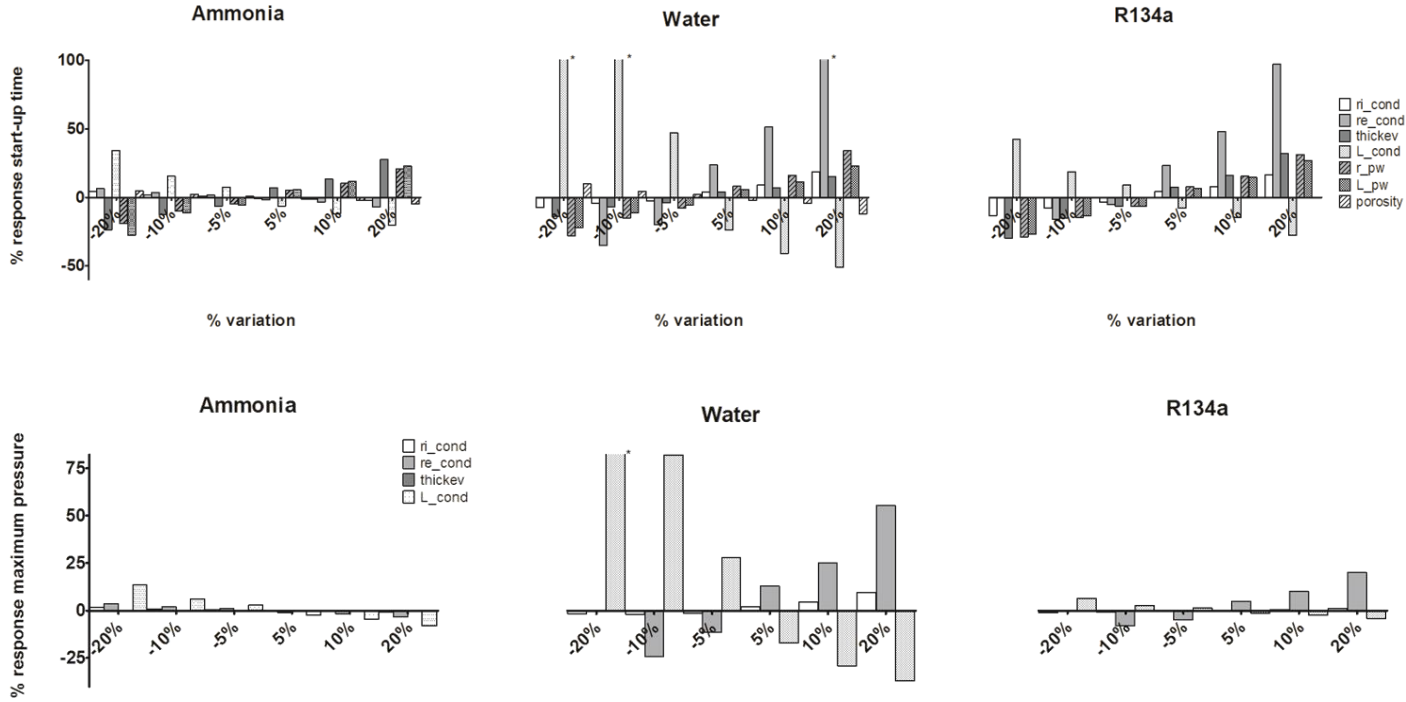

R134a

$\%$ variation

$\%$ variation

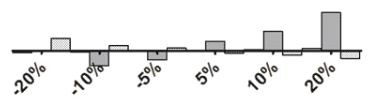

Fig. 8 - Parametric analysis results. On the y-axis there is the percentage variation of respectively vapour quality, maximum temperature, thermal resistance, start-up time and maximum pressure; on the $\mathrm{x}$-axis the percentage variation of a given geometrical parameter as shown in the legends. The $\left(^{*}\right)$ indicates that the parameter variation is out of the selected scale and it will make the graph unreadable.

\subsection{Design Guidelines}

First of all, it is evident that some of the investigated geometrical parameters such as $r_{v g}, n_{v g}, r i_{v l}, L_{v l}$ are not represented in the graphs of Fig. 8. Since the effect they provide is less than $1 \%$, they prove not to be influential parameters regarding the performances, nonetheless they remain considerable in the design process. Nevertheless, from Fig. 8 it is possible to gather some indications useful from a design 
point of view. Once the main geometrical parameters are fixed by the requirements of the application, these results can lead to small modifications able to optimize the LHP operation.

For optimization, it is assumed that one should aim to lower thermal resistance, maximum temperature and pressure for safety reasons. In order to achieve so, this investigations suggests the following design actions:

1. to consider a trade-off in terms of mass between reducing the internal radius of the condenser and increasing its length;

2. to make the condenser tube as thin as possible, compatibly with the strength requirement of the selected applications;

3. to have thicker evaporator wall and a bigger primary wick;

4. to increase porosity where possible;

5. if the weight is not a compelling factor, to increase the radius of the liquid line, also because a shorter liquid line will reduce the thermal resistance.

Moreover Fig. 8 points out that the heat leakage plays a role on thermal resistance as well, that suggests considering carefully the shape of the wicks and their coupling. However, a smaller condenser radius will cause also the LHP to react slowly to variations of the external heat load, as shown by the behaviour of the vapour quality.

\section{Feasibility Study}

The purpose of this feasibility study is to explore if an array of LHPs is able to transfer heat from a Heat Pump system positioned close to the electric motor to different locations of an FEV, namely the underbody and the cabin. This could reduce the cooling drag and improve passenger comfort, respectively. In the present investigation the case of the underbody is addressed, which represents the most demanding scenario in terms of power to be dissipated, according to industrial collaborator specifications.

In order to cool down fluids and different parts of the engine, air is usually directed under the hood generating an additional aerodynamic loss called cooling drag, which is estimated usually being around $10 \%$ of the total drag of the vehicle [27]. In an FEV, due to the lack of an internal combustion engine, there is also a lack of huge waste heat amount to be dissipated. Therefore, the under-hood flow can be instead directed to the underbody of the vehicle. Inside this underbody the condensers of the LHPs can be placed, dissipating the heat from the motor area.

The boundary conditions are defined by the geometry of the chosen vehicle and by the results of the 3D CFD simulations performed by TMETC engineers (industrial collaborator) that identified the convective heat transfer coefficients (HTC) at the underbody. From these simulations, three different zones were identified with three different HTCs. Moreover, it has been valued that such STM system needs to dissipate a nominal power of $4 \mathrm{~kW}$ and a peak power of $8 \mathrm{~kW}$. CFD simulations were performed with three different operating conditions regarding the vehicle speed, namely $30 \mathrm{~km} / \mathrm{h}, 60 \mathrm{~km} / \mathrm{h}$ and $90 \mathrm{~km} / \mathrm{h}$. For the present feasibility study, the only modification made on the LPM, is to add the conductive thermal resistance of the underbody in the overall thermal resistance of the condenser.

Two design ideas for the condenser were formulated:

- Design 1: Four equal condensers running the entire length of the underbody and subjected to the three different HTCs;

- Design 2: Three different condensers occupying one zone each and therefore subjected to a single HTC.

These two design concepts are depicted in Fig. 9. 

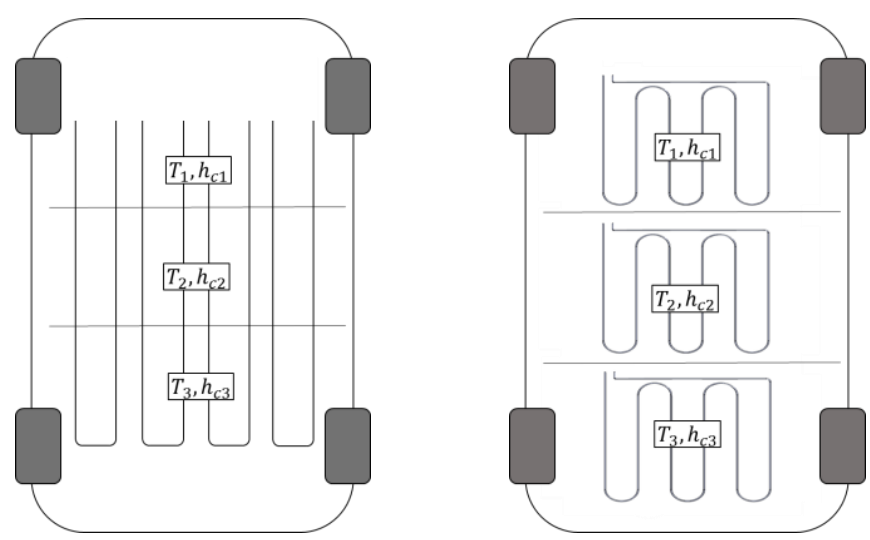

Fig. 9 - Condenser design: design 1 (left) and Design 2 (right). $\boldsymbol{T}_{\mathbf{1}}, \boldsymbol{T}_{\mathbf{2}}, \boldsymbol{T}_{\mathbf{3}}$ are the film temperatures at the underbody.

For both designs, the chosen materials are stainless steel for the pipes and the evaporator casing and nickel for the wicks, while the working fluid is water. In agreement with the best practice information found in literature, the selected filling ratio for all the simulations is $60 \%$. Following the results of this investigation are presented, firstly focused on dissipating the nominal power.

\subsection{Condenser Design 1}

This design consists in having four identical LHPs aiming to dissipate $1 \mathrm{~kW}$ each, with the condenser subjected to the three different HTC regions, as illustrated in Error! Reference source not found. (left). An optimised, final geometry was considered through an optimisation process, in order to be able to dissipate the required amount of heat.

The results of this design idea are presented in Table 2:

Table 2 - Design 1 results

\begin{tabular}{|c|c|c|c|c|}
\hline \multirow[b]{2}{*}{ Performance Parameter } & \multicolumn{4}{|c|}{ Vehicle Velocity Cases } \\
\hline & $30 \mathrm{~km} / \mathrm{h}$ & $60 \mathrm{~km} / \mathrm{h}$ & $90 \mathrm{~km} / \mathrm{h}$ & Units \\
\hline Maximum Temperature & 105 & 87 & 77 & ${ }^{\circ} \mathrm{C}$ \\
\hline Thermal Resistance & 0.0066 & 0.0053 & 0.0043 & $\mathrm{~K} / \mathrm{W}$ \\
\hline Start-up time & 1100 & 509 & 315 & $\mathrm{~s}$ \\
\hline Maximum Pressure & 0.969 & 0.489 & 0.330 & bar \\
\hline
\end{tabular}

As expected, increasing the speed of the vehicle improves the heat exchange at the underbody, since higher HTCs are encountered. Therefore, this leads to lower maximum temperature, start-up time and pressure. The total mass of the four LHPs is estimated around $12 \mathrm{~kg}$ in this case.

\subsection{Condenser Design 2}

In this case, three identical LHP condensers occupy one zone each, therefore they will be subjected to the same HTC throughout, as represented in Fig. 9 (left). In this case due to the higher HTCs in the second and third zone, the corresponding condensers radius and therefore their total mass is accordingly reduced without affecting the overall heat transfer capacity. For this design, each of the LHPs is subjected to $1.3 \mathrm{~kW}$ of external power.

The results of this design concept are presented in Table 3:

Table 3 - Design 2 results

\begin{tabular}{|l|c|c|c|c|c|}
\hline & \multicolumn{5}{|c|}{ Vehicle Velocity Cases } \\
\cline { 1 - 6 } Performance Parameter & $\mathbf{3 0} \mathbf{~ k m} / \mathbf{h}$ & $\mathbf{6 0 ~ k m} / \mathbf{h}$ & $\mathbf{9 0} \mathbf{~ k m} / \mathbf{h}$ & Units & \\
\cline { 1 - 5 } Maximum Temperature & 82 & 75 & 64 & ${ }^{\circ} \mathrm{C}$ & \\
\cline { 1 - 5 } Thermal Resistance & 0.004 & 0.003 & 0.002 & $\mathrm{~K} / \mathrm{W}$ & $\begin{array}{c}\text { Zone } \\
1\end{array}$ \\
\cline { 1 - 5 } Start-up time & 518 & 379 & 223 & $\mathrm{~s}$ & \\
\hline
\end{tabular}




\begin{tabular}{|c|c|c|c|c|c|}
\hline Maximum Pressure & 0.39 & 0.30 & 0.19 & bar & \\
\hline Mass & & & 3 & $\mathrm{~kg}$ & \\
\hline Maximum Temperature & 96 & 87 & 73 & ${ }^{\circ} \mathrm{C}$ & \multirow{5}{*}{$\begin{array}{c}\text { Zone } \\
2\end{array}$} \\
\hline Thermal Resistance & 0.0048 & 0.0043 & 0.0033 & $\mathrm{~K} / \mathrm{W}$ & \\
\hline Start-up time & 926 & 618 & 335 & $\mathrm{~s}$ & \\
\hline Maximum Pressure & 0.66 & 0.47 & 0.27 & bar & \\
\hline Mass & \multicolumn{4}{|c|}{2.7} & \\
\hline Maximum Temperature & 112 & 83 & 71 & ${ }^{\circ} \mathrm{C}$ & \multirow{5}{*}{$\begin{array}{c}\text { Zone } \\
3\end{array}$} \\
\hline Thermal Resistance & 0.005 & 0.004 & 0.003 & $\mathrm{~K} / \mathrm{W}$ & \\
\hline Start-up time & 1200 & 526 & 306 & $\mathrm{~s}$ & \\
\hline Maximum Pressure & 1.24 & 0.40 & 0.25 & bar & \\
\hline Mass & \multicolumn{4}{|c|}{2.3} & \\
\hline
\end{tabular}

Similarly with the Design 1 concept, Table 3 shows that having higher vehicle velocity enhances the heat transfer. In this case the total mass of the LHPs array is $8 \mathrm{~kg}$.

From a performance point of view, the two designs are similar, however the second design presents slightly lower values of thermal resistance and total mass. On the other hand, there is the technical complexity in the Design 2 concept since three different LHPs need to be manufactured.

\subsection{Peak Power Simulations}

Since from TMTEC evaluations the peak power for the considered STM system is estimated to be $8 \mathrm{~kW}$, it was deemed appropriate to simulate the proposed concepts subjected to the peak power for a certain amount of time. Hence, a transient heat input was provided to the first design, due its simplicity. In more detail the heat input is varied from $1 \mathrm{~kW}$ to $2 \mathrm{~kW}$ and back to $1 \mathrm{~kW}$ at $1100 \mathrm{~s}$ time intervals. For all three vehicle velocities considered the same heat input was utilized.

In Fig. 10 the results of temperature and pressure for the three velocity cases are presented:

\section{Temperature @30 km/h}

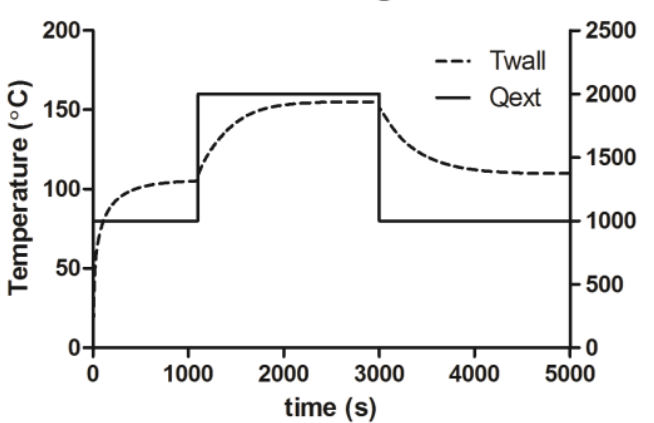

Temperature @60 km/h

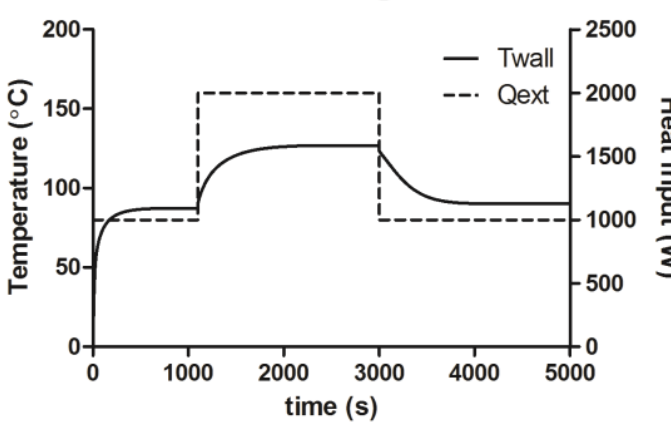

Pressure @30 km/h

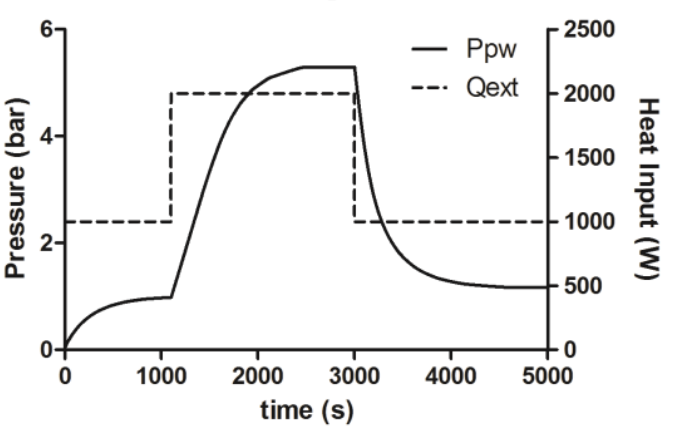

Pressure @60 km/h

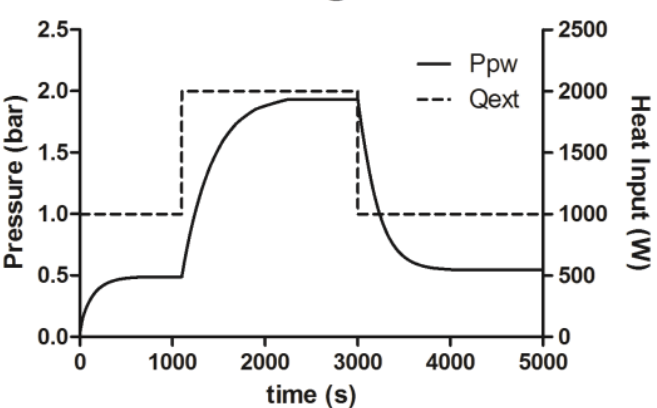



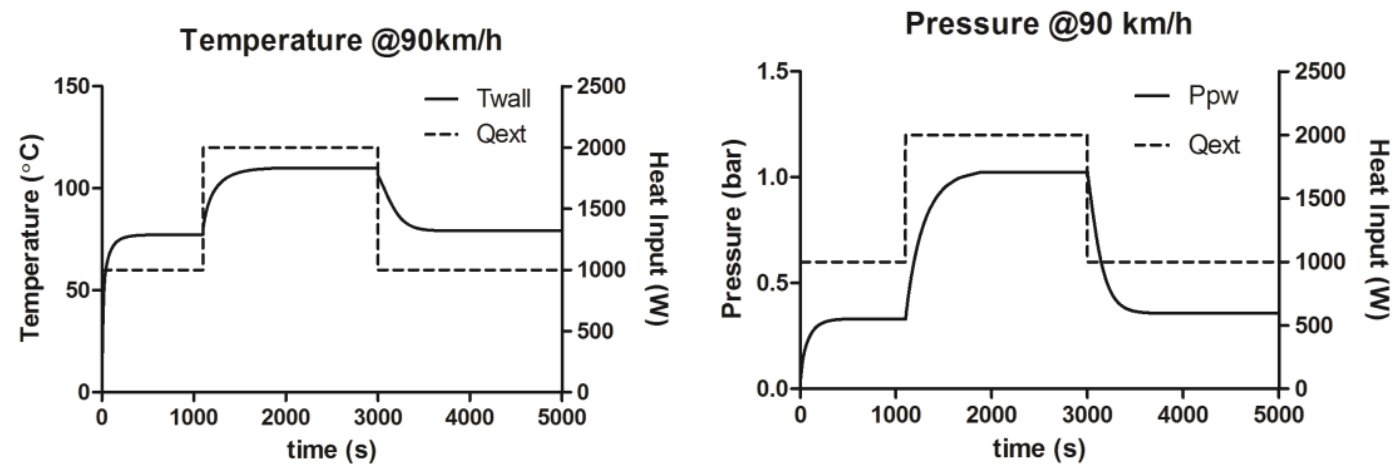

Fig. 10 - Results on the feasibility study for peak power $8 \mathrm{~kW}$ (2kW for each LHP).

From the graphs of Fig. 10 it is evident that the designed LHP can reach steady state conditions even with $8 \mathrm{~kW}$ of heat input load. However, especially at really low vehicle velocities, in order to match the increase of temperature required for dissipating the greater heat input, the pressure will reach critical levels. Therefore, this value can be supported by this LHP system only for a short amount of time (a few minutes), which stays in agreement with peak power working mode.

\section{Conclusions}

A one-dimensional model for a Loop Heat Pipe was created aiming to conduct quick feasibility studies, especially for implementing this technology in the thermal control system of a FEV. The model was developed by means of the lumped parameter methodology in order not to have significant computational requirements, in fact the code is able to maintain a computational time close to the real time of the considered phenomena. Octave, an open-source software is utilized for the implementation of the LPM. In the mathematical formulation of the model, a novel strategy that accounts for the underlined phasechange phenomena in the condenser has been formulated, using the time derivative of the vapour quality computed at each node. A validation processes has been carried out to prove the code reliability, employing literature available data. Three different configurations were examined along with three different working fluids (R134a, water and ammonia) and the results were replicated with a percentage error always less than $2 \%$ and in most cases less than $1 \%$. Furthermore, a comprehensive parametric analysis has been performed on all the geometrical LHP parameters used in the code. The single effect of each one of them was investigated looking at the performance response of the LHP. This led to a better understanding of the most influential parameters and to some important design suggestions for optimize the device operation efficiency. Finally, a feasibility study on the possibility to implement LHPs within the thermal control management system of a FEV was conducted. Two different design ideas were evaluated, proving in both cases the ability of the proposed configurations to dissipate the required heat loads. In future works, there is the need to tune the present LPNM with in-situ experimental data, in order to verify the influence of additional parameters like filling ratio, condenser geometry configuration and heat leakage estimations.

\section{Acknowledgments}

The authors would like to take the opportunity to acknowledge the financial support from Innovate UK through the INNOVATE UK LOOPER- 132232 research project. The authors would also like to thank Tata Motors European Technical Centre Plc, and in particular Stuart Dunkley, Robin East, George Hoholis and Johnathan Breddy, for the overall support and consideration.

\section{References}

[1] L.L. Vasiliev, Heat pipes in modern heat exchangers, Appl. Therm. Eng. 25 (2005) 1-19. doi:10.1016/j.applthermaleng.2003.12.004.

[2] Y.F. Maydanik, Loop heat pipes, Appl. Therm. Eng. 25 (2005) 635-657. doi:10.1016/j.applthermaleng.2004.07.010.

[3] T.T. Hoang, J. Ku, HEAT AND MASS TRANSFER IN LOOP HEAT PIPES, in: Proc. 2003 ASME Summer Heat Transf. Conf., 2003: pp. 1-9.

[4] A. Ambirajan, A. Adoni, J.S. Vaidya, A. a. Rajendran, D. Kumar, P. Dutta, Loop Heat Pipes: A Review of Fundamentals, Operation, and Design, Heat Transf. Eng. 33 (2012) 387-405. doi:10.1080/01457632.2012.614148. 
[5] Y.F. Maydanik, M.A. Chernysheva, V.G. Pastukhov, Review: Loop heat pipes with flat evaporators, Appl. Therm. Eng. 67 (2014) 294-307. doi:10.1016/j.applthermaleng.2014.03.041.

[6] Z. Wang, W. Yang, A review on loop heat pipe for use in solar water heating, Energy Build. 79 (2014) 143-154. doi:10.1016/j.enbuild.2014.04.051.

[7] B. Siedel, V. Sartre, F. Lefèvre, Literature review: Steady-state modelling of loop heat pipes, Appl. Therm. Eng. 75 (2015) 709-723. doi:10.1016/j.applthermaleng.2014.10.030.

[8] T. Kaya, R. Pérez, C. Gregori, A. Torres, Numerical simulation of transient operation of loop heat pipes, Appl. Therm. Eng. 28 (2008) 967-974. doi:10.1016/j.applthermaleng.2007.06.037.

[9] V. V. Vlassov, R.R. Riehl, Mathematical model of a loop heat pipe with cylindrical evaporator and integrated reservoir, Appl. Therm. Eng. 28 (2008) 942-954. doi:10.1016/j.applthermaleng.2007.07.016.

[10] G. Xin, L. Cheng, W. Du, T. Luan, Y. Qu, S. Zinna, M. Marengo, M. Molina, J. Burger, Modeling of a real LHP and integration in a system level analysis, SAE Tech. Pap. (2006). doi:10.4271/2006-01-2228.

[11] T. Coquard, Loop heat pipe thermal model, 16th Int. Heat Pipe Conf. (16th IHPC). (2012).

[12] M. Discacciati, P. Gervasio, A. Quarteroni, The Interface Control Domain Decomposition (ICDD) Method for Elliptic Problems, SIAM J. Control Optim. 51 (2013) 3434-3458. doi:10.1137/15M101854X.

[13] A.F. Robertson, D. Gross, An Electrical-Analog Method for Transient Heat-Flow Analysis, J. Res. Natl. Bur. Stand. (1934). 61 (1958) 105-115. doi:10.6028/jres.061.016.

[14] K.W. Oh, K. Lee, B. Ahn, E.P. Furlani, Design of pressure-driven microfluidic networks using electric circuit analogy, Lab Chip. 12 (2012) 515-545. doi:10.1039/C2LC20799K.

[15] P.J. Linstrom, W.G. Mallard, NIST Chemistry webBook, NIST Standard Reference Database Number 69, 2014. doi:citeulike-article-id:3211271.

[16] J. Ku, Loop Heat Pipe Start-up Behaviors, 46th Int. Conf. Environ. Syst. (2016) 1-18.

[17] J. Ku, Operating Characteristics of Loop Heat Pipes, 29 Th Int. Conf. Environ. Syst. (1999) 16. doi:10.4271/1999-01-2007.

[18] J. Ku, Methods of Controlling the Loop Heat Pipe Operating Temperature, in: 38th Int. Conf. Environ. Syst. San Fr. Calif. June 29-July 2, 2008, 2008.

[19] Hill Philip G., Peterson Carl R., Mechanics and thermodynamics of propulsion (2nd revised and enlarged edition), 1992.

[20] I.E. Idel'chik, Handbook of hydraulic resistance (3rd edition), Washington. (1960) 517. doi:AEC-tr- 6630.

[21] R. Sánta, The Analysis of Two-Phase Condensation Heat Transfer Models Based on the Comparison of the Boundary Condition, Acta Polytech. Hungarica. 9 (2012) 167-180.

[22] M.M. Awad, Y.S. Muzychka, Effective property models for homogeneous two-phase flows, Exp. Therm. Fluid Sci. 33 (2008) 106-113. doi:10.1016/j.expthermflusci.2008.07.006.

[23] F.P. Incropera, D.P. DeWitt, Fundamentals of Heat and Mass Transfer, Water. 6th (2007) 997.

[24] E. Pouzet, J.L. Joly, V. Platel, J.Y. Grandpeix, C. Butto, Dynamic response of a capillary pumped loop subjected to various heat load transients, Int. J. Heat Mass Transf. 47 (2004) 2293-2316. doi:10.1016/j.ijheatmasstransfer.2003.11.003.

[25] T. Tharayil, L. Godson, V. Ravindran, S. Wongwises, Effect of filling ratio on the performance of a novel miniature loop heat pipe having different diameter transport lines, Appl. Therm. Eng. 106 (2016) 588-600. doi:10.1016/j.applthermaleng.2016.05.125.

[26] B.B. Chen, W. Liu, Z.C. Liu, H. Li, J.G. Yang, Experimental investigation of loop heat pipe with flat evaporator using biporous wick, Appl. Therm. Eng. 42 (2012) 34-40. doi:10.1016/j.applthermaleng.2012.03.006.

[27] D. Baeder, T. Indinger, N. Adams, P. Unterlechner, Aerodynamic Investigation of vehicle cooling drag, SAE Tech. Pap. 2012-01-0170, 2012. (2012). doi:10.4271/2012-01-0170.

\section{List of Tables and Figures}

Table 1 - Electric analogies. $R_{\mathrm{t}}$ is the thermal resistance, $\mathrm{R}_{\mathrm{d}}$ is the pressure resistance associated to the distributed

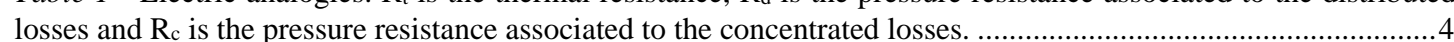

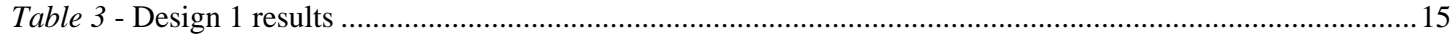

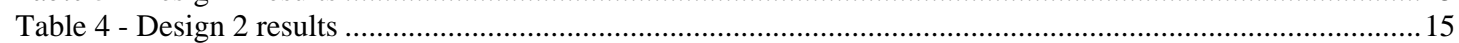

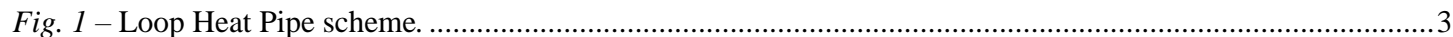

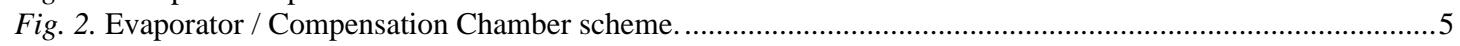

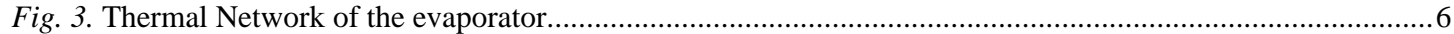

Fig. 4 - Comparison between Evaporator wall temperatures (left) and compensation chamber temperature (right) 10 Fig. 5 - Mass flow rate comparison (left) and primary wick and vapour grooves temperatures comparison (right) 10

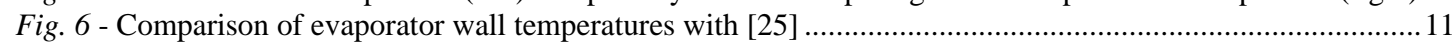
Fig. 7 - Comparison of evaporator wall and primary wick temperatures with [26], in (a) the power cycle is 10-4080-130-100-70-110-50-20-60-30 W whereas for (b) is 70-30-80-110-90-60-20-120-50-40-10 W ....................... 12 Fig. 8 - Parametric analysis results. On the y-axis there is the percentage variation of respectively vapour quality, maximum temperature, thermal resistance, start-up time and maximum pressure; on the $\mathrm{x}$-axis the percentage variation of a given geometrical parameter as shown in the legends. The $\left(^{*}\right)$ indicates that the parameter variation is out of the selected scale and it will make the graph unreadable. 
591

592

593

594

595
Fig. 9 - Condenser design: design 1 (left) and Design 2 (right). T1, T2, T3 are the film temperatures at the

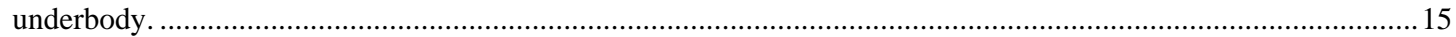

Fig. 10 - Results on the feasibility study for peak power $8 \mathrm{~kW}$ (2kW for each LHP)...................................... 17 